\title{
A prospective randomised control study on dynamic compression plating versus intra medullary interlocking nailing in humeral diaphyseal fractures
}

\author{
Muhammed Junaid Abdul, Jojin Jose Chitten*, \\ Ramasamy Balasubramaniam, Rajamohan Rajesh
}

Department of Orthopaedics, Sri Venkateshwaraa Medical College and Research Centre, Pondicherry, India

Received: 16 March 2021

Accepted: 25 March 2021

*Correspondence:

Dr. Jojin Jose Chitten,

E-mail: jojinjosec@gmail.com

Copyright: ( ) the author(s), publisher and licensee Medip Academy. This is an open-access article distributed under the terms of the Creative Commons Attribution Non-Commercial License, which permits unrestricted non-commercial use, distribution, and reproduction in any medium, provided the original work is properly cited.

\begin{abstract}
Background: Surgical fixation of humeral shaft fractures generally involves plating or nailing. Despite the extensive literature comparing outcomes after open reduction with internal fixation (ORIF) with plating and interlocking intramedullary nailing (ILIMN) for acute humeral diaphyseal fractures, the superior treatment strategy still remains controversial. The purpose of this study was to compare the functional outcome of each method of fixation (dynamic compression plating and interlocking nailing) for the shaft of humerus fracture and to analyse statistically significant difference in the results of these two methods in terms of functional outcome, rate of healing and complications.

Methods: We conducted a prospective randomized control study and evaluated the results of 50 patients having humeral shaft fracture which were internally fixed with antegrade interlocking nailing (25 patients) and dynamic compression plating (DCP) plate (25 patients). Patients were followed up on average of 11.4 months and their radiological outcomes were assessed with plain radiography and with DASH score.

Results: The plating group had statistically significant faster radiological healing and better DASH score compared to nailing group. Also, postoperative complication rate was higher in ILN group which was statistically significant.

Conclusions: ORIF with DCP provides better results in terms of good functional outcome, faster radiological union and less post-operative complications compared to ILIM nailing. Hence, we concluded that plating is a superior option than nailing.
\end{abstract}

Keywords: Humerus fracture, Interlocking intramedullary nail, DCP, ORIF, DASH score

\section{INTRODUCTION}

Humeral diaphyseal fractures account for nearly $3 \%$ of all orthopaedic injuries. ${ }^{1,2}$ The majority of these fractures used to be treated non-operatively before with predictably good rate of union and functional outcome, but prolonged immobilisation of the limb was needed resulting in delayed return to professional and recreational activities. ${ }^{2}$ The recent advancement in implant designs and internal fixation techniques has led to wide expansion of the indications for surgical intervention for these fractures, generating new debate on implant of choice.

Definitive operative intervention for acute traumatic humeral shaft fractures generally consists of either ORIF with DCP or interlocking intramedullary nailing ILIMN. ${ }^{1-}$ 3 Both these methods have their own advantages and disadvantages. Plating provide rigid anatomical fixation of the fracture, but it requires extensive soft tissue dissection with periosteal stripping which can reduce the blood 
supply leading to risk of non-union and infection. Meanwhile, latest generation of IMIL nails has provided improved technique in treatment for humeral diaphyseal fractures than the previous generations..$^{2,4,5}$ Recent studies have recommended that intramedullary nailing can be considered as standard surgical method through either antegrade or retrograde approach. Theoretically closed nailing is considered as minimally invasive with shorter operative time and minimal intraoperative blood loss . But rotator cuff damage associated with antegrade nailing can lead to shoulder impingement and restricted range of motion. In addition, iatrogenic comminution at the fracture site and iatrogenic stretching of the radial nerve during nailing are also reported. ${ }^{1,2,6}$

Despite there are studies available comparing functional outcomes of these two methods of fixation for humeral diaphysis, the superior treatment strategy between these two is still controversial. The purpose of this study was to find out which method is better in terms of functional outcome and perioperative complications.

\section{METHODS}

We conducted a prospective randomized control trial study from December 2018 to May 2020. A minimum sample size of 34 (17 in each groups) was calculated for the study with reference to the study conducted by Nikunj Modi et al with power of $80 \%$ and Confidence interval of $95 \%$ on the basis of excellent results given by DASH Score. ${ }^{7}$ $\mathrm{P} 1=43 \%$ (excellent DASH Score by DCP group) and $\mathrm{P} 2=12 \%$ (excellent DASH Score by IMILN group).

The aim of the study was to compare the results of dynamic compression plating and interlocking nailing in the treatment of shaft of humerus fracture with reference to rate of healing, functional outcome and complications. After getting institutional scientific research committee clearance and institutional ethical committee clearance and written informed consent, we selected patients above 18 years of age with humerus shaft fracture admitted for surgical management. We excluded patients treated with other than compression plate or interlocking nail, those with pre-existing shoulder and elbow pathology, pathological fractures of humerus and those patients who were lost to follow up or expired during the study period.

For avoiding bias, first patient was selected by lottery method to decide on which method to be used and the second patient was given the alternate method and the remaining patients were alternated with in a similar manner. Any preoperative complications were recorded.

Fractures were classified according to AO classification of fracture shaft of humerus. The humeral shaft fracture was temporarily immobilized with a U-slab and arm pouch. The group of plating underwent the procedure using either anterolateral or posterior approach to the humerus. The fracture was fixed with $4.5 \mathrm{~mm}$ narrow DCP in all the patients. The group of nailing underwent the procedure using antegrade approach to the humerus. On the first postoperative day the adequacy of fixation was evaluated using plain radiography and if found satisfactory active shoulder and elbow mobilization was started. All the patients in both the groups received 3 days of standard antibiotic protocol of intravenous cefaperazone-sulbactum 1.5 gram twice daily and intravenous gentamycin of $5 \mathrm{mg}$ per $\mathrm{kg}$. The wound was inspected for all the patients on the third post-operative day and the patient was discharged on the fourth post-operative day if there were no peri-operative complications. Wound was re-evaluated on the 10th postoperative day and sutures were removed if the wound found to be healed. All the patients were clinically evaluated using DASH score and with plain radiography at 1 month, 3 months and 6 months follow up. ${ }^{8}$ Assessment of DASH score was done by a separate orthopaedic consultant for single blind technique to eliminate subjective bias.

The duration for clinical and radiological union was noted. If there are no signs of clinical and radiological union after 16 weeks of fracture considered as delayed union and if the absence of union of fracture even after 32 weeks after injury are categorized as non-union. The data was statistically analyzed by using SPSS version. ${ }^{9}$ The descriptives were measured in terms of mean, SD, frequency and proportion such as age, sex and radiological outcome analyzed by student $\mathrm{T}$ test. The functional outcome with DASH Score was analyzed by independent chi-square test ( $\mathrm{p}$ value).

\section{RESULTS}

A total of 54 patients with unilateral closed shaft of humerus fractures were selected in the study as per the inclusion criteria, out of which two patients were lost to follow up and two had expired. The remaining 50 patients with distribution of 25 each in DCP and in interlocking nailing group were followed up as per the study plan.

In the IMILN group there were 19 males and 6 females and the DCP group had 18 males and 7 females. On applying chi square test, the p value was found to be 0.747 , which is not statistically significant, indicating no significant difference in the sex pattern in the two groups.

Age of the patients in the IMIL nailing group ranged from 22 to 60 years with a mean of 38.72 years and the age in the dynamic compression plating ranged from 23 to 70 years with a mean age of 38.08 years. By applying the student $t$ test the $p$ value of $0.846(p>0.05)$ which showed that there was no statistically significant difference in the age distribution of the two groups as well. 


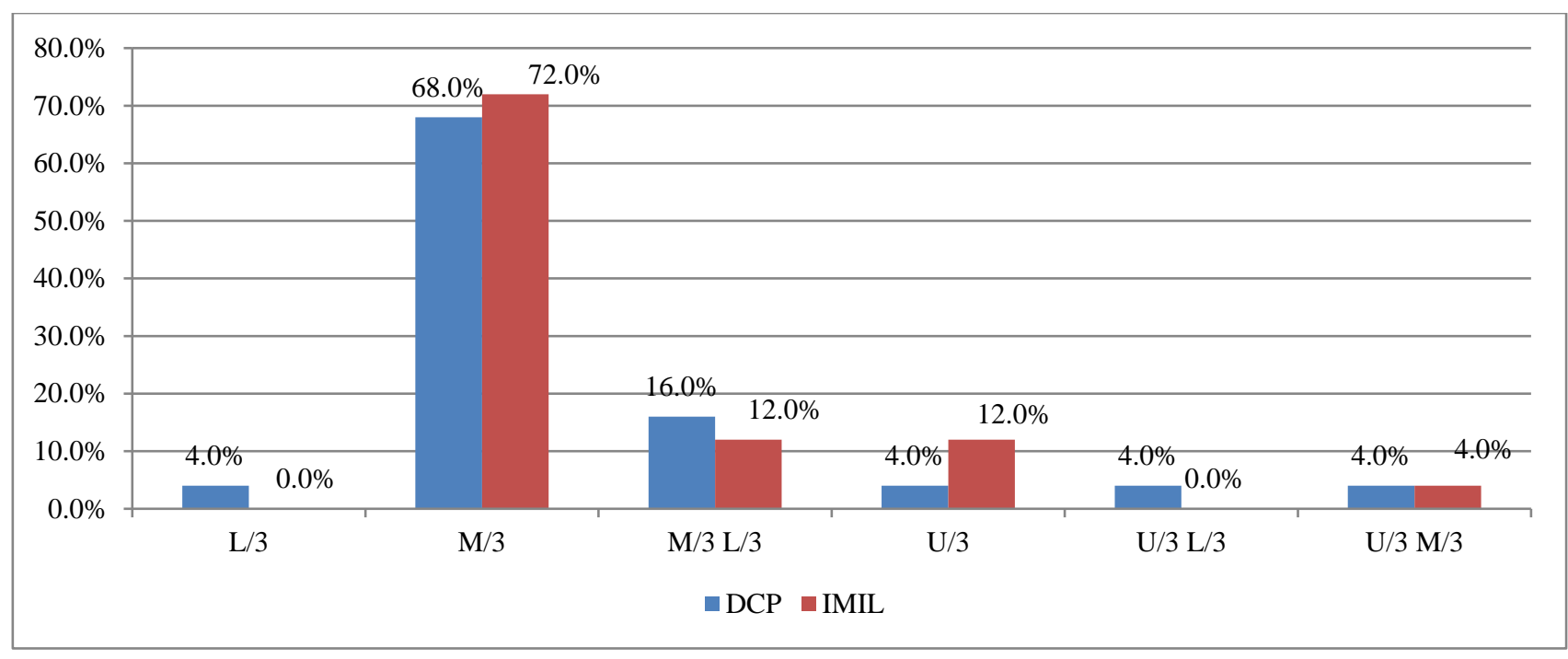

Figure 1: Level of injury.

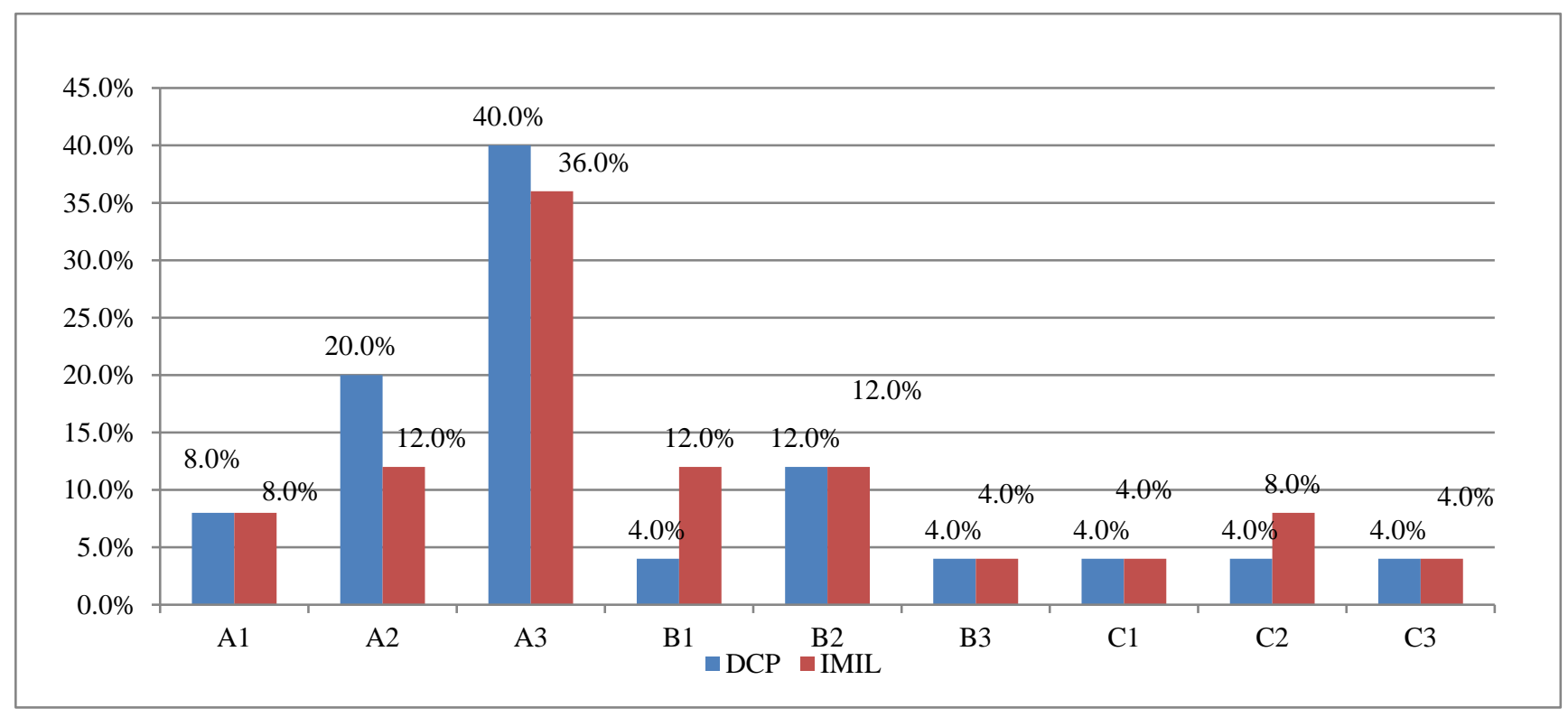

Figure 2: AO classification.

The most common mode of injury in both groups is RTA with domestic fall being the second most common cause. Right side was most commonly involved side in both the DCP and interlocking group with no statistically significant difference.

Regarding the anatomical location of the fracture, 35 fractures occurred in the middle third of the diaphysis, 17 in the DCP group and 18 in the IMILN group. Seven fractures in the middle one third and lower one third junction, 4 fractures in the upper third region, 2 fractures between upper third and middle third junction, 1 segmental fracture that extending between upper one third and lower one third and 1 fracture was in lower one third of the shaft, as depicted in Figure 1.
The fractures were segregated as per AO classification which is shown in Figure 2. There were 15 type A fractures in IMILN group and 17 in DCP group: 7 type B fractures in the IMILN group and 5 in DCP group and 3 type $\mathrm{C}$ fracture in the DCP and 3 in the ILIMN group.

Regarding associated injuries, the ILIMN group had 7 injuries of which 4 were lower limb fractures, 1 distal radius fracture, 1 clavicle fracture and 1 abdominal injury. Out of the 12 associated injuries in the DCP group, 8 were lower limb fractures, 1 distal radius fracture, 1 rib fracture, 1 abdominal injury and 1 patient had paraplegia secondary to vertebral fracture and spinal cord injury.

Pre-operative radial nerve palsy was observed in three patients. All three of them were in the DCP group out of which two of them had full functional recovery. 


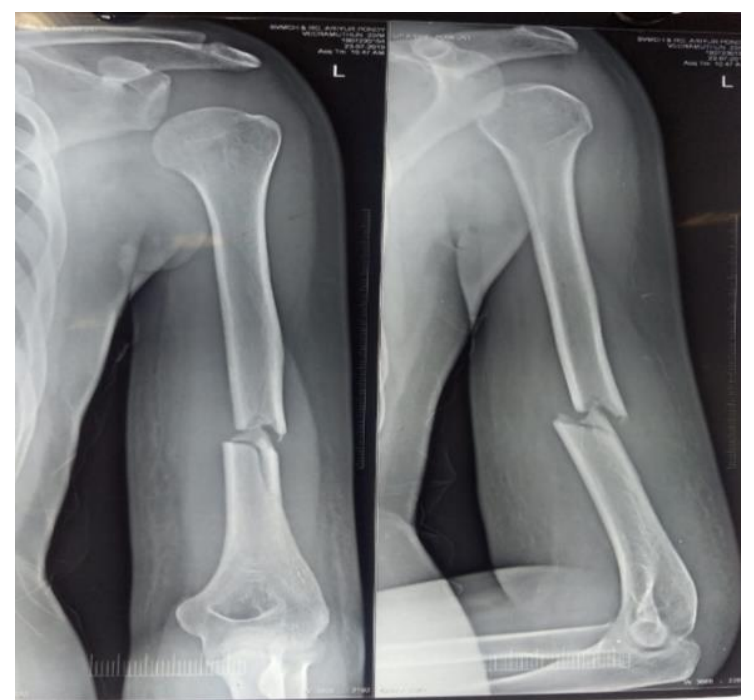

Figure 3: Pre-operative plain radiography.

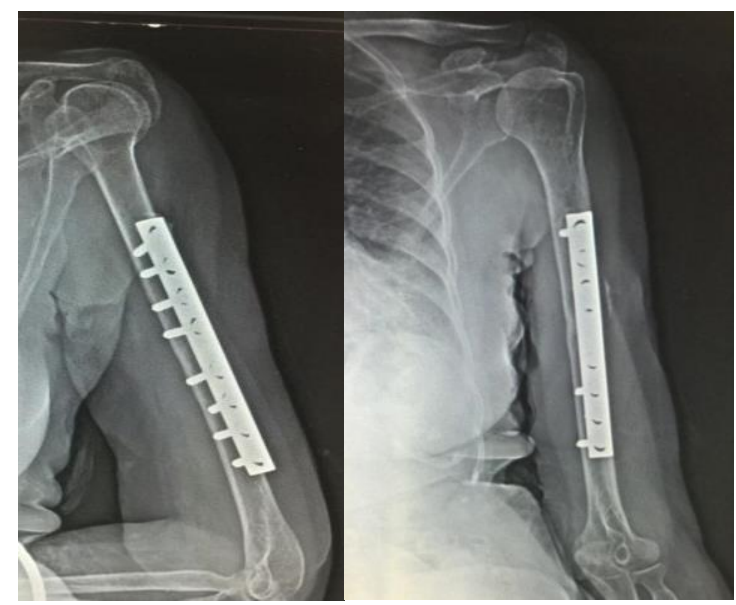

Figure 4: Post operative follow up at 6 months after DCP fixation.

The mean duration between trauma and surgery was 4.15 days in DCP group and 2.95 days in IMIL nailing, the total average being 3.52 days.

In DCP group, anterolateral approach was used in 14 patients and posterior approach was used in 11 patients.
The average time taken for surgery was 86 minutes for DCP and 75 minutes interlocking nailing group.

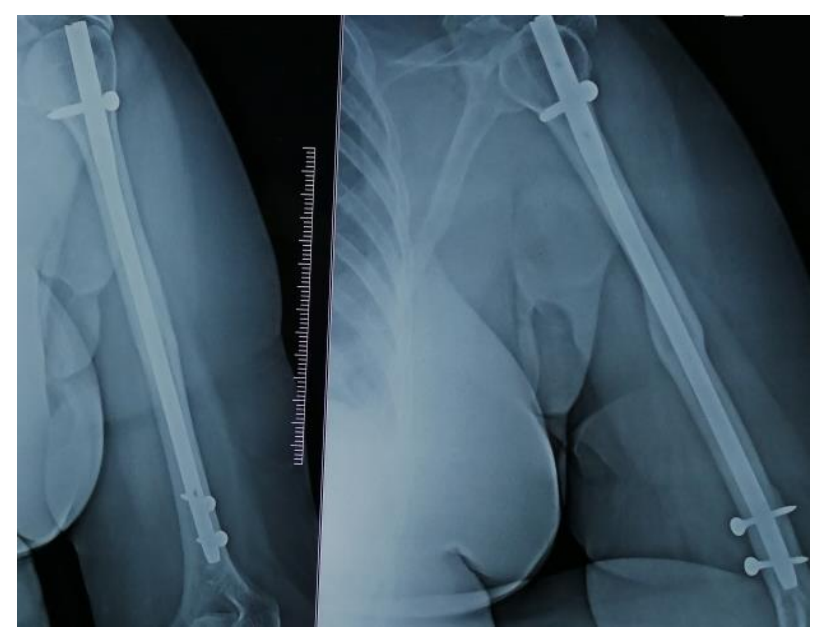

Figure 5: Post-operative follow up at 6 months after nailing.

The average duration of follow up in our study was 11.4 months; range (6 to 17 months). The average duration taken for radiological healing in the nailing group was 15.2 weeks and 11.75 weeks in DCP group; the mean being 13.47 weeks (Figure 3-5). So, the healing rate was relatively faster in the DCP group as compared to the IMILN group and there was statistically significant difference in the time taken for radiological union $(\mathrm{P}=0.0001)$. Two fractures treated with IMILN progressed to non-union and both of which underwent revision surgery with ORIF with plating and bone grafting.

The DASH scores of 0 to 20 was considered as excellent, 21 to 40 is good, 41 to 60 was taken as fair and above 61 was considered as poor. The average DASH score of the whole series was 32.16 (lower the DASH score better the function). The average DASH score in the DCP group was 23.60 and in the interlocking group it was 40.72. The results were statistically significant with p value of 0.003 . Among the 50 patients 16 had excellent results, 16 had good results, 12 had fair results, 6 had poor results (Table 1 and 2).

Table 1: Comparison of DASH scores.

\begin{tabular}{|lllllll|}
\hline Results & Excellent & Good & Fair & Poor & Total & P value \\
\hline DCP & 10 & 8 & 4 & 3 & 25 & 0.046 \\
\hline IMIL & 6 & 8 & 8 & 3 & 25 & SIG \\
\hline Total & 16 & 16 & 12 & 6 & 50 & \\
\hline
\end{tabular}

Table 2: Statistical analysis of DASH scores.

\begin{tabular}{|c|c|c|c|c|c|c|c|}
\hline & $\mathbf{N}$ & Minimum & Maximum & Mean & SD & $\begin{array}{l}\text { Mann-Whitney } \\
\text { z value }\end{array}$ & P value \\
\hline IMIL & 25 & 0.00 & 80.00 & 40.72 & 18.50 & \multirow{2}{*}{-3.0} & \multirow{2}{*}{0.003} \\
\hline DCP & 25 & 0.00 & 68.00 & 23.60 & 20.49 & & \\
\hline
\end{tabular}


Table 3: Intraoperative complications.

\begin{tabular}{|c|c|c|c|c|}
\hline \multirow{2}{*}{ Intra operative problems } & \multicolumn{2}{|l|}{ Group } & \multirow[b]{2}{*}{ Total $(\%)$} & \multirow{2}{*}{ P value } \\
\hline & $\operatorname{DCP}(\%)$ & IMIL (\%) & & \\
\hline Fracture greater tuberosity with lateral cortex & $0(0)$ & $1(4.0)$ & $1(2.0)$ & \multirow{7}{*}{$0.267 \mathrm{NS}$} \\
\hline Difficult reduction of fragments & $0(0)$ & $1(4.0)$ & $1(2.0)$ & \\
\hline Comminution at fracture site & $1(4.0)$ & $0(0)$ & $1(2.0)$ & \\
\hline No complications & $24(96.0)$ & $21(84.0)$ & $45(90.0)$ & \\
\hline Problem in locking & $0(0)$ & $2(8.0)$ & $2(4.0)$ & \\
\hline Radial nerve entrapment in fracture segments & $0(0)$ & $0(0)$ & $0(0)$ & \\
\hline Total & $25(100)$ & $25(100)$ & $50(100)$ & \\
\hline
\end{tabular}

Table 4: Postoperative complications.

\begin{tabular}{|c|c|c|c|c|}
\hline \multirow{2}{*}{ Post-operative complications } & \multicolumn{2}{|l|}{ Group } & \multirow[b]{2}{*}{ Total $(\%)$} & \multirow{2}{*}{ P value } \\
\hline & $\operatorname{DCP}(\%)$ & IMILN (\%) & & \\
\hline Impingement & $0(0)$ & $4(33.3)$ & $4(25.0)$ & \multirow{5}{*}{$0.045 \mathrm{SIG}$} \\
\hline Implant failure & $1(25.0)$ & $2(16.6)$ & $3(18.7)$ & \\
\hline Non union & $1(25.0)$ & $2(16.6)$ & $3(18.7)$ & \\
\hline Shoulder pain & $0(0)$ & $2(16.6)$ & $2(12.5)$ & \\
\hline Shoulder stiffness & $1(25.0)$ & $1(8.3)$ & $2(12.5)$ & \\
\hline Superficial infection & $1(25.0)$ & $1(8.3)$ & $2(12.5)$ & \\
\hline Total & $4(100)$ & $12(100)$ & $16(100)$ & \\
\hline
\end{tabular}

In our study, intraoperative complications were found to be statistically insignificant (Table 3), but the postoperative complications were found to be more in nailing group than the DCP group which was found to be statistically significant (Table 4).

\section{DISCUSSION}

Though humerus shaft fractures are fixed with either DCP or interlocking intramedullary nailing, there is no clear census consensus regarding which is a better option for faster fracture healing and functional recovery.

In our study, the incidence of humerus shaft fractures is found to be more in males than females, the most common age group being in the third decade. The trend is similar in majority of other studies. ${ }^{10,11,12}$

Our study shows plating with DCP is superior in terms of faster radiological union, better functional outcome and reduced post-operative complications.

The average fracture healing time in our study was found to be 11.75 weeks for plating group and 15.2 weeks for nailing group. The findings are concurrent with recent studies done by Gupta et al and Saroj et al on similar set of patients. ${ }^{2,3}$ While the former group showed radiological union of 3 months for plating and 4 months for nailing; the latter group showed faster healing by 1 month in plating compared to nailing. There may be delay in union in nailing group due to distraction at the fracture site which usually occurs during nail insertion in contrast to plating where a complete contact between the fracture ends is achieved with compression principle.
Our findings of better functional outcome and less complications in the DCP group is consistent with study done by Dai et al in which they concluded that nailing may cause more method-related complications and shoulder impairment than plating. ${ }^{12}$ Similarly, study done by Saroj et al also showed better functional results in the DCP group than nailing. ${ }^{3}$

Meta-analysis by Wang et al showed that functional measurement was significantly better for plate fixation along with significantly lower risk of complications, delayed-union, restriction, shoulder impingement, shoulder pain and re-operation and hence suggested that plating is superior to IMN for humeral shaft fractures. ${ }^{5}$

However, Ouyang et al conducted a meta-analysis in 2013 and concluded that both plating and nailing can achieve similar outcomes. ${ }^{13}$ But compared with plating, nailing incurs a greater risk of complications related to the shoulder function which was similar to our study. Similarly, another meta-analysis in 2015 by Zhao et al proved that the differences between IMIL nail and ORIF plate fixation were not significant in fracture union, radial nerve injury and infection. ${ }^{14}$ But IMIL nail significantly increases the risk of shoulder complications (shoulder impingement and restriction of shoulder movement) and revision surgery. Hence, they concluded that plate fixation is superior to intramedullary nail for the treatment of humeral shaft fractures.

Our study shows no statistically significant difference in intra operative complications, but there is significant difference in the case of post-operative complications especially shoulder function impairment favoring plating. 
The poor outcome in intramedullary interlocking nailing group is attributable to rotator cuff tear and shoulder impingement. Nevertheless, in 2016, Gottschalk et al studied a similar set of patients 12 and concluded that the overall complication rates in ORIF with plating and ILIM nailing remains relatively low on the basis of cohorts. The ORIF with plating cohort having higher incidences of infection and nerve palsy and the IMN cohort having higher incidences of post-surgical complications. Similarly, Gupta et al and Saroj et al concluded that nailing appears to be better than plating in terms of less chance of infection, less blood loss, less chance of nerve injury and less chance of implant failure..$^{2,3}$

Also, there are few studies which shows equivocal results between plating and nailing. Studies done by Wali et al and Eduardo Benegas et al proved that there was no significant difference between the two groups in terms of union or complications. ${ }^{15,16}$ Similarly, in a study done by Wen et al, his meta-analysis showed that there was no significant difference between plating and nailing. ${ }^{13}$ It also showed higher risk of restriction of range of motion of shoulder and elbow joints in the nailing group but it had the added advantage of lesser operative time and shorter hospital stay. Though statistically insignificant our study also showed shorter average operating time in nailing group than the plating group.

\section{CONCLUSION}

Based on our operative results and follow up of cases, we concluded that ORIF with dynamic compression plates was found to be superior to intra medullary interlocking nailing for the management of shaft humerus fractures, in terms of better functional outcome, faster radiological union and less post-operative complications.

\section{Funding: No funding sources \\ Conflict of interest: None declared \\ Ethical approval: The study was approved by the institutional ethics committee}

\section{REFERENCES}

1. Zarkadis NJ, Eisenstein ED, Kusnezov NA, Dunn JC, Blair JA. Open reduction-internal fixation versus intramedullary nailing for humeral shaft fractures: An expected value decision analysis. J Shoulder Elbow Surg. 2018;27(2):204-10.

2. Gupta P, Jain N. Humerus midshaft fractures-nailing or Plating? A prospective study over 60 patients. J Bone Joint Dis. 2018;33(3):18-21.

3. Saroj DK, Nagaich A, Gupt P. Comparative study of results of ORIF with plating vs CRIF with nailing in fracture midshaft humerus. Int $\mathbf{J}$ Orthop Sci. 2020;6(1):1-4.

4. Singisetti K, Ambedkar M. Nailing versus plating in humerus shaft fractures: a prospective comparative study. Int Orthop. 2010;34(4):571-6.
5. Wang X, Chen Z, Shao Y, Ma Y, Fu D, Xia Q. A meta-analysis of plate fixation versus intramedullary nailing for humeral shaft fractures. J Orthop Sci. 2013;18(3):388-97.

6. Walker M, Palumbo B, Badman B, Brooks J, Van Gelderen J, Mighell M. Humeral shaft fractures: a review. J Shoulder Elbow Surg. 2011;20(5):833-44.

7. Modi N, Pundkar GN. Comparative study of functional outcome of dynamic compression plating with intramedullary interlocking nailing in close fracture shaft of humerus in adults. J Res Med Dent Sci. 2015;3(4):298-302.

8. Cocco LF, Ejnisman B, Belangero PS, Cohen M, Reis FB. Quality of life after antegrade intramedullary nail fixation of humeral fractures: A survey in a selected cohort of Brazilian patients. Pat Safety Surg. 2018;12(1):4.

9. Chapman JR, Henley MB, Agel J, Benca PJ. Randomized prospective study of humeral shaft fracture fixation: intramedullary nails versus plates. J Orthop Trauma. 2000;14(3):162-6.

10. Balfour GW, Mooney V, Ashby ME. Diaphyseal fractures of the humerus treated with a ready-made fracture brace. J Bone Joint Surg Am. 1982;64(1):11.

11. Gottschalk MB, Carpenter W, Hiza E, Reisman W, Roberson J. Humeral shaft fracture fixation:Incidence rates and complications as reported by American board of orthopaedic surgery part II candidates. J Bone Joint Surg Am. 2016;98(17):e71.

12. Tetsworth K, Hohmann E, Glatt V. Minimally invasive plate osteosynthesis of humeral shaft fractures: current state of the art. J Am Acad Orthop Surg. 2018;26(18):652-6.

13. Dai J, Chai Y, Wang C, Wen G. Dynamic compression plating versus locked intramedullary nailing for humeral shaft fracture: a meta-analysis of RCTs and nonrandomized studies. J Orthop Sci. 2014;19(2):282-91.

14. Ouyang H, Xiong J, Xiang P, Cui Z, Chen L, Yu B. Plate versus intramedullary nail fixation in the treatment of humeral shaft fractures: an updated meta-analysis. J Shoulder Elbow Surg. 2013;22(3):387-95.

15. Zhao J, Wang J, Wang C, Kan S. Intramedullary nail versus plate fixation for humeral shaft fractures: A systematic review of overlapping meta-analyses. Medicine. 2015;94(11):599.

16. Wali MG, Baba AN, Latoo IA, Bhat NA, Baba OK, Sharma S. Internal fixation of shaft humerus fractures by dynamic compression plate or interlocking intramedullary nail: a prospective, randomised study. Strategies Trauma Limb Recononstr. 2014;9(3):13340.

Cite this article as: Abdul MJ, Chitten JJ,

Balasubramaniam R, Rajesh R. A prospective randomised control study on dynamic compression plating versus intra medullary interlocking nailing in humeral diaphyseal fractures. Int J Res Orthop 2021;7:461-6. 